\title{
Time to Engage? Texting to Support and Enhance First Year Undergraduate Learning
}

\author{
$\underline{\text { doi:10.3991/ijim.v3i2.744 }}$ \\ G.M. Jones and G. Edwards \\ University of Bath, Bath, United Kingdom
}

\begin{abstract}
In this paper we discuss a case study investigating how the academic and personal development of first year students on an undergraduate sports education degree can be supported and enhanced with mobile SMS communication. SMS-based technologies were introduced in response to students' particular needs (in transition to Higher Education) and characteristics ('digital natives'). Despite being unaccustomed to using their mobile phones for academic study, students willingly participated in SMS communication with their tutor via a texting management service. Drawing on evidence from two student surveys, focus groups and a tutor's journal, we illustrate the potential that mobile SMS communication has to link and establish continuity between face to face teaching sessions and online learning activities in the Virtual Learning Environment (VLE). Many students perceived the SMS communication to have had a positive impact on their management of study time. We link our findings with the existing literature and argue that mobile text based communication has the potential to support the development of time management skills, an important component of self regulatory learning, a skill which has been shown to be key in making a successful transition.
\end{abstract}

Index Terms-SMS, mobile phones, transition to HE, time management, text management service

\section{INTRODUCTION}

The latest generation of undergraduates have grown up in a world of pervasive digital technology which, it is claimed, has caused them to develop fundamentally different ways of thinking and processing information from their predecessors and their teachers [1]. Widespread ownership of mobile devices have provided an infrastructure that these students rely on for building extensive social communication networks [2] in ways unfamiliar to their tutors. Arguably these disconnects compound the challenge of supporting students at vulnerable points in their academic development, for example, when making the transition to the new and sometimes alien social and academic environment of Higher Education (HE).

Mobile learning (m-learning) opportunities are thought to offer alternative or complementary modes of learning that more closely match student preferences. Many pilot or demonstrator (proof of concept) m-learning projects have illuminated the potential for mobile devices to support learning and change in $\mathrm{HE}$ approaches [3]. Typically these might involve the use of high specification devices running specialist software packages and/or focus on using mobile devices as part of highly student-centred learning experiences at remote locations rather than in traditional learning settings. Few studies have explored how to harness existing infrastructures of personal mobile devices for study purposes. Furthermore, little is known about how mobile mediated communication might complement more traditional learning and teaching contexts (e.g. lectures, seminars and more recently and increasingly, within Virtual Learning Environments, (VLEs)).

In this paper we offer a case study that illuminates the role of mobile SMS and issues associated with embedding this communication in an academic course of study. We focus on the theme of how texting in support of time management can help students in transition.

\section{A. Transition to HE modes of study}

There is now growing recognition that higher priority must be given to addressing the needs of students during their transition into HE [4]. New students face a variety of challenges associated with $\mathrm{HE}$ modes of study where academic demands and teaching arrangements differ from their previous experiences in school. First year students often report differences between the degree of support they received before and the support they receive in $\mathrm{HE}$ where they are expected to rely more heavily on their own efforts [5]. Placed in an academic environment in which self-direction and independence in learning are emphasised, in contrast to more didactic approaches experienced in secondary education, many students feel isolated and insecure. Reference [6] notes that in the UK around ten per cent of full-time HE students withdraw during or at the end of their first year, and that lack of selfmanagement skills is commonly given by young students withdrawing [7].

Taking responsibility for improving one's learning and becoming an independent learner is typically assumed to be a requisite for success in $\mathrm{HE}$ [8]. In general, selfregulation is assumed to be a process in which an individual plans, organises, self-instructs, self-monitors and evaluates at various stages of the learning process [9]. However, comparing major self-regulation models in education Boekaerts \& Corno [10] concludes that there is no simple or straightforward construct, as each model emphasises different aspects of self-regulation. Certain basic assumptions shared by cognitive, volitional and socio-cultural models nevertheless are that students construct their own meanings, goals and strategies (see ref. [11]) ; and that they are capable of monitoring and managing aspects of their own cognition, motivation, behaviour and learning environment. The link between self-regulated learning and academic achievement has long been established (see for example ref. 12 and ref. 13). Indeed Reference [14] summarises that self-regulation 
research focusing on cognitive strategies such as monitoring, organising and managing time has indicated that self-regulated learning is seen as a mechanism to help explain achievement differences among students and as a means to improve achievement.

It is noteworthy that whilst there are large volumes of material available marketed at the 'time-poor', and whilst there is wide endorsement of good time management practices in organisations and workplaces, it appears that few studies have actually tested the empirical validity of basic time management principles, particularly in a university environment [15]. Reference [16] established how poor time management was a perceived cause of examination failure by university students, and reference [17] found that good time management practices were correlated to higher college grades. Other studies have compared time management skills and academic performance of mature and traditional-entry university students and found that though mature students reported better time management scores, the difference between the age groups in terms of skills did not translate into differences in academic performance [18], [19]. Whilst reference [20]'s study concludes that recognition of individuality of the students was more important than time management skills, reference [21] demonstrates that time management behaviours may not be linked directly to stress or stress related outcomes, but instead operate through the perception of control over time. Poor time management has been cited as contributing to students' withdrawal from university or failing by reference [22].

There are, however some general insights which can be gleaned from the literature devoted to time management, particularly in relation to time management behaviours. These may also be informative in the context of university students' management of time: having a clear purpose (in study at $\mathrm{HE}$ ), planning and organising, avoiding interruptions and distractions, and being organised (adapted from [15]). Such behaviours point to the need for students to be motivationally and behaviourally active participants in their learning [23], rather than being subject to what reference [24] have termed 'victimitis, nearsightedness and priority malnutrition' (p654). Reviewing research into the characteristics of students who self-regulate their learning, reference [25] concurs that 'what characterises self-regulating students is their active participation in learning.' (p3), and more specifically that 'they plan and control the time and effort to be used on tasks' (op cit). These authors further contend that with adequate training all students can improve their degree of control over learning and performance.

\section{B. Digital 'natives', and mobile communication}

Prensky's [26] conception of the divide between digital 'natives' and 'immigrants' has alerted the world of education to the ways that students fundamentally think and process information differently from their predecessors. Arguing that the 'immigrant' teachers' assumptions of what learners should be and the methods that should work are no longer valid, Prensky suggests that in relation to methodology and content a radical rethink is required for 'all subjects', 'at all levels, using our students to guide us' (p.6). While Prensky's model has been discussed and his initial categories embellished further [27], few would disagree with the basic tenet that narrowing the gap between the teacher ('immigrant' or 'tourist') and the 'native' student is a key concern as we consider the impact of technology. Moreover, in Wesch's YouTube portrayal [28] of contemporary life as a student in the USA, students report that time spent on daily activities (e.g. on the phone, watching TV, working, studying etc.) adds up to more than 24 hours. Wesch also alludes to complex social communication network that competes for time with more academic pursuits ("I will read 8 books and 1281 facebook profiles this year"). The multitasking habits of this generation of students have been widely discussed (for example [29]) sometimes viewed as an asset or as detrimental.

A key question then is whether or not alternative or complementary modes of learning, such as m-learning, might better support contemporary students. Mobile phones can now be considered as pervading the UK student population with Ofcom [30] reporting that, in 2006, $96 \%$ of the UK population in the 15-24 age group personally used a mobile phone. More provocatively, the Horizon Report [31] predicts that the capabilities of mobile phones are increasing rapidly, and the time is approaching when these little devices will be as much a part of education as a bookbag.' It is timely to investigate how these devices can be meaningfully orchestrated into $\mathrm{HE}$ learning experiences. However, we concur with Corbeil and Valdes-Corbeil [32], that changes as a result of introducing m-learning are likely to be 'evolutionary rather than revolutionary’, as shown in our case study.

M-learning can be defined in many ways depending on the focus on the learner, technology, or learning context. For the purposes of this study, we interpret m-learning as 'learning in a mobile society, with a focus on how society and its institutions can accommodate and support the learning of an increasingly mobile population' [33]. Our interest is in how mobile phones and specifically SMS can complement and enhance traditional HE education at key times, such as during transition to HE.

A few studies report on the efficacy of SMS in HE. Stone et al.'s [34] experiments reveal the effectiveness of SMS in gaining attention. They observed that $50 \%$ of a 1000 student sample had responded to an SMS within 30 minutes, the first responses arriving within 10 minutes. Other studies report on the use of SMS within teaching and learning. Reference [35] suggests that using mobile phones and SMS for academic administration had a positive impact on student drop out rate, keeping distance learning students on track and supporting 'at risk' students. Pastoral support is also the focus of Horstmanshof's [36] work in Australia and Harley et al.'s [37] in the UK, the latter specifically in relation to students transitioning to HE. Both studies demonstrate student willingness to accept their tutors as participants in informal SMS communication about their courses of study. Horstmanshof made her mobile number available and encouraged students to make contact, while Harley et al. took a more structured approach and planned messages to be sent out at times when they thought students would be feeling vulnerable. Harley et al. suggest that one way students support each other is by engaging in an SMS dialogue of checking with peers about what is expected of them. Also, we have found students check email and notices on a VLE relatively infrequently compared to text messages. Overall these researches are encouraging with respect to student willingness to use SMS outside a purely 
social context, and the positive psychological impact of using a highly personal medium.

\section{CASE STUDY}

\section{A. Context}

We focus on a first year unit entitled 'Exploring Effective Learning' in the Coach Education and Sports Development Undergraduate Programme at the University of Bath. The aims of the unit are to identify effective approaches to learning, and develop student understanding of the learning process in the context of study in HE. The unit is well-established, where teaching consists of two hours contact per week, with an expectation of students mirroring this in regular independent study. The unit attracts students from other departments, such as psychology and social sciences. Coach Education students in particular experience challenges with transition as there are extra demands on their time, due to the need to train and perform (travel to competitions, training camps, etc). Most students are resident on campus, where they have access to an extensive wireless network. Evaluations from previous cohorts indicate that the students experience difficulty in sustained engagement with independent study tasks.

\section{B. Aims}

By structuring inter-session study time using group learning activities [38] we aimed to establish networked opportunities for learning that more effectively support the student experience on this unit and motivate student participation. In addition we sought to harness the communication cultures and skills of these 'digital native' students, using mobile phones and SMS to promote greater connectivity between the students and the tutor.

\section{Preliminary Investigation}

We surveyed the new students $(n=56)$, prior to arrival on campus to elicit data about the extent of mobile phone ownership, the capability of their devices, and the range of contracts or licenses under which they operate, student cultures and skills surrounding their use, alongside the students' willingness to adopt mobiles as tools to support their learning.

1) How available are students for mobile contact via SMS?

The majority of students own high specification mobiles. Surprisingly few seemed to use anything more than basic capability (SMS and voice calls). Students responded they were almost always available for communication via their mobiles. They reported checking for messages frequently (every 20min, $1 \mathrm{hr}$, several times a day) and always responding to the arrival tone.

2) How useful did students think their mobiles would be for activities connected with learning?

Students saw particular potential for keeping in contact with their tutor and in receiving questions or reminders about deadlines from their tutor (Fig. 1)

3) How frequently would students be prepared to receive texts connected with their courses?

Most students were prepared to receive texts several times a week. (Fig. 2)
4) How many messages would students be willing to send in connection with their course?

Many students were willing to use some of their own quota of text messages for study purposes. (Fig. 3)

In addition, 93\% of students are willing for their mobile numbers to be stored securely by their department.

In summary it seemed that the vast majority of students would welcome contact with tutors and receiving reminders about deadlines; they were willing to use some of their own texts for study purposes and to receive texts connected with a course of study.

\section{Implementation}

These findings and our literature review informed the initial design learning activities incorporating texting. The activities integrated the two dominant learning contexts for students on this unit: face-to-face sessions and the VLE. Asynchronous tools (forums and wikis) were used in concert with mobile communication, managed through a texting service to support both individual and collaborative processes.

The initial survey provided us with clear guidance regarding the students' views of acceptable use of text messaging for learning, especially volume, timing and purpose of the texts. The text messaging component of the integrated learning activities was constructed within these parameters: the messages (Fig. 4) acted as reminders to engage with preparatory and follow-up activities located in the VLE, and associated with face-to-face sessions.

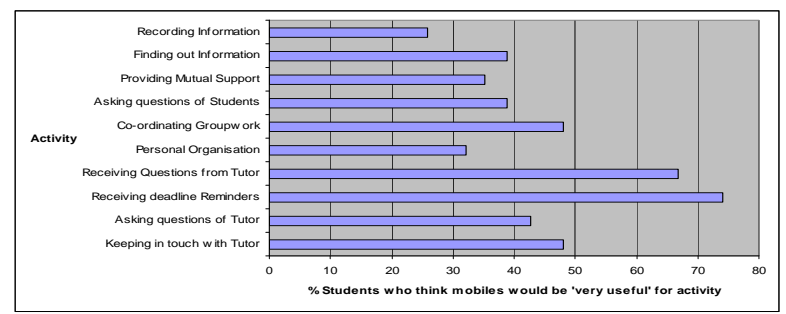

Figure 1. Student views about the potential for using mobile phones to support learning

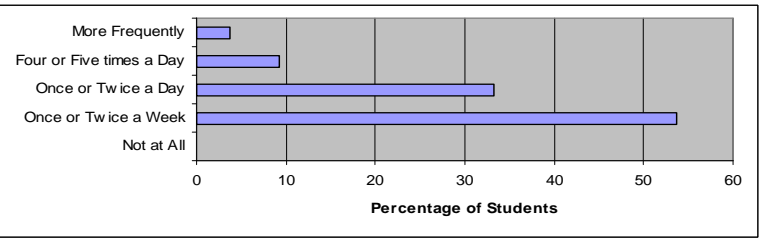

Figure 2. Student willingness to receive text messages connected with their course

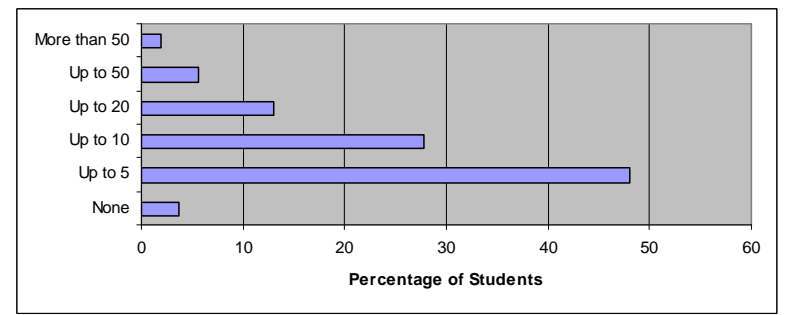

Figure 3. Number of course related messages students were willing to send each week 
Students received no more than two texts a week. To achieve efficient management and distribution of the messages, a texting management service (Edutext) was used, enabling composition, scheduling and sending of personalised text messages via a web interface. In addition, students were requested to send one SMS message in response to a preparatory task. (Fig. 5)

\section{E. Early Student Feedback}

In the early stages of the unit we shared our plans with the students and requested feedback via an online forum. Student participation was good (31) and comments were made about the usefulness of the texts for reminders and deadlines. The few areas of concerns were: with costs (11); restrictions of 160 characters (4), volume (3). At this point we implemented an opt out, by texting "NO Reminders" to the course mobile number. Only one student said they would take this up.

\section{F. Refining the Implementation}

During the semester we continued a week-by-week formative evaluation through informal and formal (focus group) consultation with students and our own ongoing tutor reflections (weekly diary), addressing: pedagogical considerations of the appropriateness of texting in relation to the desired learning outcomes; volume and quality of students' texts responses to learning activities; changes in the quality of student engagement; attendance in face-toface sessions and online; coherence of the integrated learning activities, and reliability of the texting management service. There were no major problems with how the texting was being received by students (e.g. frequency of texts out to students and requests for text responses) and feedback was generally confirmatory regarding the efficacy of the texting activities.

As a result of student feedback in the focus group, for example, students' text contributions were then presented by a 'word cloud' to aid the extraction of meaning.

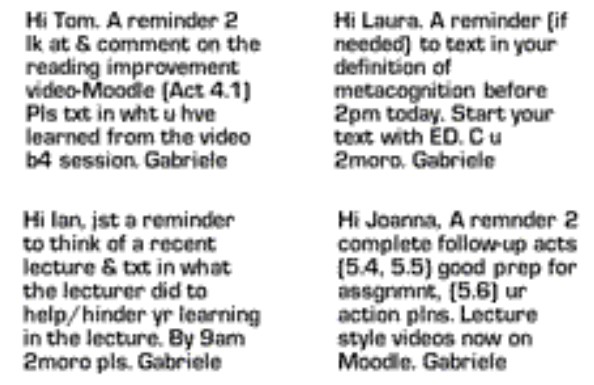

Figure 4. Examples of text messages sent to students

i have learnt how The sq3r strategy could help me 2 read aswel as actually takin in the info \& learning at the same time e.g. Taking notes at same time

The lecturer is willing to answer any questions that anyone has, and uses specific language that students will understand.

Figure 5. Examples of text messages received from students

\section{G. Summary of Findings}

A comprehensive questionnaire was administered at the end of the unit (50 questions, both qualitative and quantitative). The response rate was $88 \%(n=81)$. Access statistics from the VLE and the texting management service and the tutor's journal also contributed to our evaluation. Overall, students highly valued the text messages as part of this unit, only two chose to opt out of receiving SMS. Predominantly they took positive actions with the texts e.g. acting on it, saving it, only $11 \%(n=71)$ chose to ignore or delete messages from the unit. The VLE and texting management service statistics suggested that the texts successfully and consistently guided students to the intersession learning activities.

Students regarded the texts as reminders about work to be done, important deadlines, administrative changes, etc, and regarded them as an effective aid to time management $(62 \%, n=71)$, especially in the busy first few weeks of term. They felt that the texts were better than email at gaining their attention and that they clarified instructions that can easily be missed at the end of face-to-face sessions. Students liked the personal nature of the texts and suggested that they would be an appropriate way for personal tutors to keep in touch. However on a few occasions, texts arrived at inconvenient or inappropriate times (and then students felt 'nagged'). Few students had strong general feelings about receiving texts and only a minority $(13 \%, n=71)$ expressed negative reactions to them. They were less supportive of sending texts in as part of learning activities and found it a challenge to be concise when restricted to 160 characters. Inhibitors to making responses by text included no credit $(24 \%, n=55)$ or were associated with doubts about task efficacy. In a few cases, lack of signal on campus was a problem and some students found themselves locked into poor network coverage.

Our evaluation showed that texting did prompt student responses to directions and questions from their tutor. There was a correlation between the time the text messages were sent out and students' arrival and subsequent activity in the VLE, in some cases students would visit the VLE just a few minutes after receiving their message. When asked about how well the face-toface teaching, the VLE and the texts had worked together, $74 \%(n=71)$ thought they had worked well or very well together. Also, in response to being asked about what the texting had added to their learning on the unit, student comments were predominantly about convenience/accessibility/gaining attention (36\%, $n=59)$ or about the effects of the texts as prompting them to take action $(32 \%, n=59)$.

\section{DISCUSSION}

Students in this study identify good time management as being an important contributor in successful transition to HE. Repeatedly during our evaluation, students connected the value of the text messaging with issues of time management. It was notable that few chose to opt out of receiving text messages, the predominant reason for not opting out being their usefulness as reminders. This is surprising, as prior to our study (initial questionnaire), students did not often use their mobile phones for receiving reminders, therefore indicating that in the academic context, SMS reminders offered sufficient utility 
for them to be accepted by almost all students as a new way of using their phone.

Empirical research elsewhere has shown that academic success can be linked to a variety of aspects of time management. For example reference [19] distinguishes between daily planning and long term planning skills in their survey of first year undergraduate and report a positive correlation between confidence in long term planning and academic success. Reference [39] also finds that first year students' confidence in their time management skills is a significant factor in determining retention, while reference [21] has shown that belief about the degree of control over time is positively linked to academic success. It is interesting to reflect on the affordances and constraints of SMS communication with respect to supporting positive time-management processes in the context of our case study.

We noted that the regular pattern of text message exchanges over the semester created temporal partitions for student activity. Reference [21] suggests that this kind of scheduling of learning activities can help students develop positive beliefs about being in control of time. This may go some way to explaining why our students showed such a positive response to the SMS communication.

Two major features of the SMS communication are important here: the immediate gaining of attention, and the ease with which items can be saved and reviewed. When asked about how SMS had helped time management specifically, student comments focused on being prompted to do something, e.g. developing a schedule. Students distinguished between a 'prompt' and what might be considered a 'to do list', perhaps indicating different levels in time management strategies. Whether immediate action in response to texts, or planning action for later, it is noteworthy that reminders via SMS can support students in a progression from having no time management strategy at all, to starting to develop a distinct self-regulating strategy. Both the early and the later focus group discussed how they responded to the texts, and we noted different strategies appeared to emerge. For example: Student $\mathrm{S}$ - receiving a text while playing computer games - switches tasks; $\mathrm{H}$ - keep it on my phone for later; A - likes to see the whole weeks' worth of tasks and regards texting as not significant in her personal organisation. Indeed different individual approaches to time management have been noted in the research literature, for example May [40] as cited in [20].

"certainly in all time planning, one thing which needs to be taken into account is the fact that different individuals have different ways of working, different tolerances of time pressure and require different degrees of urgency to produce their optimal best performance. Time deadlines have a varied significance to individuals."

Individual approaches to time planning may therefore be influencing the actions students take with incoming text messages. Indeed, it may be be that the value placed on particular aspects of the texting may change as students become more self-regulating. In terms of the importance placed on the development of generic study skills, our study appears to have facilitated the beginnings of personal attributes fostering a successful transition. On the other hand, it might be argued that students become reliant on reminders, which in turn might inhibit self-regulating strategies, a view expressed by Horstmanshof's colleagues [36], a concern we share to an extent. In the focus groups and online forum about the project, students discussed possible consequences of becoming dependent on text reminders, and specifically, whether or not becoming habituated to receiving reminders might mitigate against the development of more independent approaches to study. However, we saw there to be considerable benefits outweighing any possible negative effects at this early stage in the transition. In future, we envisage students being offered more choice in the type and frequency of receiving reminders, thereby enabling them to progress towards more sophisticated time management strategies. Finally, this might lead to students proactively setting their own reminders using the diary or scheduler functionality on their phones, a functionality which all their mobiles support. Further research into how these students (as 'digital natives') develop effective time management strategies will help to refine our use of SMS for this aspect of transition. In particular, we need to know more about how and whether students incorporate a world increasingly populated by digital alerts (driven primarily by rss technology) into their time management.

\section{CONCLUSION}

The need to manage out of session study time and effectively engage in academic work while distant from a tutor is challenging for students in transition to HE modes of learning. The support structure provided by the text based communication was successful in addressing these challenges by scaffolding a time management regime that fostered greater awareness of students' need to develop self-regulating strategies.

Criticisms mounted against mobile devices in academic contexts such as encouraging superficial communication and thinking [41] have not been born out in our case study. Learning activities requiring students to respond via SMS often produced thoughtful results and when texts were collected and aggregated (e.g. as word clouds) this provided a spark for further discussion.

The extensive functionality of today's highly flexible personal mobile communication devices can be seductive, causing us to lose sight of the task in hand: that of providing effective learning experiences for our students. Here we have demonstrated that keeping grounded in the learning process, students' lifeworlds and the research literature rather than the technology has helped to appreciate the small but key role played by the simple text message in providing temporal cues for active learning. Crucially important to our study has been the ongoing negotiation of mutually appropriate modes of texting associated with the students' academic course of study, and the willingness of the tutor to become involved in the digital 'native' world of SMS communication.

\section{ACKNOWLEDGMENTS}

This paper was first presented at the Networked Learning Conference 2008. We would like to thank Dr Alan Reid (Department of Education, University) for his help and support during this research.

\section{REFERENCES}

[1] D. Oblinger \& J. Oblinger, Eds, Educating the Net Generation. Educause 2005. 
http://www.educause.edu/books/educatingthenetgen/5989 [viewed 20 Jan 2008]

[2] D.J. Reid \& F.J.M. Reid, "Textmates and text circles: Insights into the social ecology of SMS text messaging”. in Mobile World A. Lasen \& L.Hamill, Eds. Springer: London, 2005, pp. 105-118 (doi:10.1007/1-84628-204-7_7)

[3] J. Cook et al., "Generating learning contexts with mobile devices." in Mobile Learning: towards a research agenda N. Pachler Ed., London: WLE Centre IoE. 2007 (pp 55-73).

[4] D. Kember, "Beliefs about knowledge and the process of teaching and learning as a factor in adjusting to study in higher education," Studies in Higher Education, vol. 26, pp. 205-221, 2001. (doi:10.1080/03075070120052116)

[5] R. Teese, "Bridging the gaps between secondary and tertiary education,” Paper presented at the Mind the Gap Conference, University of Melbourne, 23 September 2002.

[6] M. Yorke, "Formative Assessment - the Key to a Richer Learning Experience in Semester 1” Exchange, vol. 1, pp. 12-13, 2002

[7] M. Yorke, Leaving early: undergraduate non-completion in Higher Education, London: Falmer Press, 1999.

[8] J. Allan \& K. Clarke, "Nurturing Supportive Learning Environments in Higher Education Through the Teaching of Study Skills: To Embed or Not to Embed?” International Journal of Teaching and Learning in Higher Education, vol. 19(1), pp. 6476, 2007.

[9] M. van den Hurk, "The relation between self-regulated strategies and individual study time, prepared participation and achievement in problem-based curriculum" Active Learning in Higher Education, vol.7, pp 155- 169, 2006. (doi:10.1177/14697874060 64752)

[10] M. Boekaerts \& L. Corno, "Self-regulation in the Classroom: A Perspective on Assessment and Intervention”, Applied Psychology: An International Review, vol. 54 (2) pp 199-231, 2005. (doi:10.1111/j.1464-0597.2005.00205.x)

[11] P. R. Pintirch, "The Role of Goal Orientation in Self-regulated Learning” in: M Boekarts, P R Pintirch \& M Zeidner (eds) Handbook of Self-regulation, Mawah, NJ: Lawrence Erlbaum, 2000, pp 451-502. (doi:10.1016/B978-012109890-2/50043-3)

[12] R. Riesenberg \& B.J. Zimmerman, "Self-regulated Learning in Gifted Students,” Roeper Review, vol.15 (2) pp. 98-101, 1992

[13] P.R. Pintirch \& T.Garcia "Student Gaol orientation and selfreguatlion in the College Calssroom" in Advances in Motivation and Achievement: Goals and Self-regulatory processes, M L Maehr \& P R Pintirch (eds), 1991, pp. 271-401. Grennwich, CT: JAI press.

[14] D.H. Schunk \& B.J. Zimmerman (Eds.), Motivation and selfregulated learning: Theory, research, and applications. Mahwah, NJ: Lawrence Erlbaum, 2007

[15] H. Kearns \& M. Gardiner, "Is time well spent? The relationship between time management behaviours, perceived effectiveness and work-related morale and distress in a university context" Higher Education Research \& Development, vol. 26(2) pp. 235247, 2007 (doi:10.1080/07294360701310839)

[16] J. Ling, T.M. Hefferman \& S.J. Muncer, "Higher Education students' beliefs about the causes of exam failure: A network approach," Social Psychology of Education vol. 6 (2) pp. 159-170, 2003. (doi:10.1023/A:1023289908438)

[17] B.K. Britton \& A. Tesser, "Effects on time-management practices on college grades," Journal of Educational psychology, vol. 83 (3), pp. 405-410, 1991. (doi:10.1037/0022-0663.83.3.405)

[18] J.T.E. Richardson, "Mature students in higher education: academic performance and intellectual ability," Higher Education vol. 28, pp. 373-386, 1994 (doi:10.1007/BF01383723)

[19] M. Trueman \& J. Hartley, "A Comparison between the TimeManagement Skills and Academic Performance of Mature and Traditional-Entry University Students," Higher Education, Vol. 32, No. 2, pp. 199-215, Sep., 1996 (doi:10.1007/BF00138396)

[20] B. Ho, "Time Management of final year undergraduate English projects: supervisees' and the supervisor's coping strategies" System, vol.31, pp.231-245, 2003. (doi:10.1016/S0346-251X(03 $\lcm{00022-8}$
[21] S. Nonis, "The relationship of perceived stress and academic performance to perceived control of time,” Marketing Education Review, Vol. 7, Number 1, Spring 1997.

[22] K. Fitzgibbon \& J. Prior, "Student Expectations and University Interventions - A timeline to aid undergraduate student retention," paper presented at LTSN BEST Conference, April 2003

[23] J. Biggs, "Teaching for Quality Learning at University”. Maidenhead: SRHE, 2003.

[24] K. Matejka, R.J. Dunsing \& B. Walat, "The seven habits of highly defective people” Management Decision vol. 36(10), pp. 654-656, 1998. (doi:10.1108/00251749810245309)

[25] F. Torrano, \& M.C.G. Torres, "Self-regulated learning : Current and future directions," Journal of Research in Educational Psychology, vol. 2 (1), pp1-34, 2004.

[26] M. Prensky, Digital Natives, “Digital Immigrants," On the Horizon. NCB UP, vol. 9(5), October 2001.

[27] C. Toledo, ”Digital culture: immigrants and tourists responding to the natives' drumbeat," International Journal of Teaching and Learning in Higher Education, vol. 19(1), pp. 84-92, 2007

[28] M. Wesch, “A Vision of Students Today," YouTube 2007 http://mediatedcultures.net/ksudigg/?p=122 [viewed 15 Jan 2008].

[29] C. Wallis, “The Multitasking Generation,” TIME.com, 2006.

[30] Ofcom “The Consumer Experience Research Report,” 2007 http://www.ofcom.org.uk/research/tce/ce07/research07.pdf [viewed 18 Jan 2008].

[31] The New Media Consortium, “The Horizon Report”: 2007 Edition. Stanford, CA.

[32] J.R. Corbeil \& M.E. Valdes-Corbeil, “Are you ready for mobile learning?” 2007 http://www.educause.edu/ir/library/pdf/EQM0 726.pdf [viewed 12 Dec 2007]

[33] M. Sharples, "Learning for the mobile age," in The Sage Handbook of E-learning Research, C. Haythornthwaite \& R. Andrews (Eds), London: Sage, 2007, (pp 221-247).

[34] A. Stone, J. Biggs \& C. Smith, "SMS and Interactivity and its implications on effective uses of mobile technologies in education," Proceedings of the IEEE International Workshop on Wireless and Mobile Technologies in Education, 2002.

[35] J. Nix, J. Russell, \& D. Keegan, "Mobile learning/SMS academic administration kit,” Paper Presented at the EDEN Take Learning Mobile conference, IADT, Dublin, September 2007.

[36] L. Horstmanshof, "Using SMS as a way of providing connection and community for first year students," in Beyond the comfort zone: Proceedings of the 21st ASCILITE Conference, R. Atkinson, et al. (Eds), (pp. 423-427). Perth: 5-8 December, 2004.

[37] D. Harley et al., "Using texting to support students' transition to university," Innovations in Education and Teaching International, vol. 44(3), pp. 229-241, 2007. (doi:10.1080/14703290701486506)

[38] JISC “Innovative Practice with E-learning”. Bristol: HEFCE, 2005.

[39] J. Goldfinch \& M. Hughes, "Skills, learning styles and success of first-year undergraduates,” Active Learning in Higher Education vol. 8, pp. 259-273, 2007. (doi:10.1177/1469787407081881)

[40] D. May, in Working for a Doctorate: A Guide for the Humanities and Social Sciences: N. Graves, (Ed.), Routledge, London, pp. 5975 ,

[41] R. Mason \& F. Rennie, E-learning and social networking handbook: Resources for HE. Oxon:Routledge, 2008.

\section{AUTHORS}

G. M. Jones is e-learning officer in the Department of Education at the University of Bath (e-mail: g.m.jones@ bath.ac.uk).

G. Edwards is a teaching fellow in the Department of Education at the University of Bath (e-mail: g.edwards@bath.ac.uk).

This work was supported by a University of Bath teaching development fund grant. The article was modified from a presentation at the mLearn2008 Conference, 8th - 10th October 2008 hosted by the University of Wolverhampton. Manuscript received 30 November 2008. Published as submitted by the authors. 